\title{
Crop Planning Models with Symmetric Risk Measures
}

\author{
Marius RĂDULESCU ${ }^{1}$, Constanţa Zoie RĂDULESCU ${ }^{2}$ \\ ${ }^{1}$ Institute of Mathematical Statistics and Applied Mathematics, \\ Casa Academiei Române, \\ 13, 13 Septembrie Avenue, Bucharest 5, RO-050711, ROMANIA, \\ mradulescu.csmro@yahoo.com \\ 2 National Institute for Research and Development in Informatics, \\ 8-10 Marshal Averescu Blvd., Bucharest 1, RO-011455, ROMANIA, \\ radulescucz@yahoo.com
}

\begin{abstract}
In this paper the financial risk of crop plans is measured by two symmetric risk measures: variance and mean absolute deviation of the return. Several crop planning models with symmetric risk measures, based on the financial portfolio theory, are formulated. Among them minimum risk and maximum expected return models are of interest. The decision variables are the land areas allocated to crops. The models belong to mathematical programming with continuous variables. Some numerical examples for the minimum financial risk model are studied and efficient frontiers of the models are displayed.
\end{abstract}

Keywords: crop planning, symmetric risk measures, portfolio theory, efficient frontier, decision support

\section{Introduction}

Agriculture today enjoys a special attention in all the countries since it contributes to their economic development. In today's world most economically developed countries are also the largest producers and exporters of basic agricultural products. Due to the cyclical nature of agricultural product prices, farmers are often faced with management challenges. When crop prices are low and margins are small, crop planning is increasingly important as farm managers strive to maximize net farm income.

The decisions connected to what crops to grow and the land areas allocated to each crop to plant, are complex management decisions. Each year, farm managers go through a process of deciding what crops to grow on each field.

When farmers are making crop plan decisions the primary consideration is economics. However once they have determined the crops that will provide the highest net returns they will often consider rotations, weed problems, herbicide residues and various other factors.

One of the main objectives when a crop plan is made is to find the combination of crops that will provide the maximum expected net returns per hectare. Another main objective is connected to the minimization of farmer income variability. It is important to consider the crops with higher expected net return in terms of risk and probability of achieving the highest level of net return. Many of the specialty crops are higher risk crops and usually require greater managerial input and marketing skills in order to achieve this higher net return. When making long term planning, decisions farmers should calculate, for all crops that are considering growing, the total revenue, total expenses and return, over total expenses.

Prospective growers must know how to use risk management strategies in order to select the crops that best suit their needs. One of the most popular approaches to managing risk is to reduce risk exposure through diversification. The uncertainty from the agriculture problems is modeled with the help of probability theory. Many of the practical problems that occur in agriculture are modelled with stochastic programming. Most of the problems that appear in crop planning have multiple objectives. In practice, in the process of mathematical modeling, one cannot take into account all the factors that have an impact to agricultural production. The number of such factors is large and the growth of their number determines the rapid growth of the complexity of the models. An important mathematical instrument which was successfully applied to modeling the problems from agriculture is portfolio theory. The above mentioned theory is widely used in to determine investment strategies under uncertainty. It shows how investments in different assets can be combined in a portfolio with a lower risk.

The application of portfolio theory for finding an optimal allocation of crops to agricultural 
land is popular in the literature. The first application of the portfolio theory to crop planning goes back to Freund [6]. In Hardaker [8], Hazell [9], Hazell and Norton [10] and Blank [2]-[4] were presented or applied various variants of portfolio theory to the land allocation decisions. In Collender [5], Romero [17]-[19], were studied several models for resources allocation in agriculture that are taking into account specific risks. In Werners et al. [21] portfolio theory was used for the evaluation of agricultural land use, as an adaptation to climate risk in the Hungarian Tisza River Basin. The main climate related risk in the Tisza is the frequent occurrence of floods and droughts.

In Barkley et al [1] portfolio theory was used to find the optimal, yield-maximizing and risk-minimizing combination of wheat varieties in Kansas.

In Nalley [12] portfolio theory is applied to wheat varietal selection decisions in order to find risk-minimizing outcomes. The selection of wheat varieties, through portfolio theory, offers producers in low-income countries the potential to increase yield or decrease yield variability. Farmers in low-income countries often value yield stability as much as yield potential. They frequently have a choice of several wheat varieties to sow and must evaluate the tradeoff between yield, mean and variance. Using location-specific empirical data, portfolio theory can provide producers in low-income countries a tool for developing a recommended varieties portfolio given a desired risk-aversion level.

Usually, in the crop planning models, the risk is measured by variance. In this case the risk becomes a quadratic function. The minimum risk model is a QP model. In Hazell [9] was developed a linear alternative to the quadratic model that uses variance as a measure for risk. The Hazell's model was called the MOTAD (Minimization Of Total Absolute Deviation) model. The computational advantage of the MOTAD is that it can be transformed in an equivalent linear programming model. The MOTAD model is extensively used in international studies in recent decades Hardaker et al [8]; Zia [22], McCarl [11], Zimet and Spreen [23], Vadnere and Padney [20].

For other references regarding applications of portfolio theory to agriculture see Radulescu [13], [14] and [16].
Our research is focused on the formulation of several original models for crop planning, based on financial portfolio theory. To evaluate risk of the net return we use two symmetric risk measures: the variance and the mean absolute deviation. We formulate two minimum financial risk models and two maximum expected net return models. In contrast to the models developed in Radulescu and Radulescu [14] and Radulescu et al. [16], which are binary and respectively mixed-binary, the models from the present paper are formulated in continuous variable. Our models can be embedded as modules in a decision support system for crop planning. Some numerical examples for the minimum financial risk model are studied and efficient frontiers of the models are displayed. The models are solved with QP and LP solvers from GAMS.

\section{Crop Planning Models}

In the following are formulated two multiple objective models for crop planning in agriculture. The models take into account weather risks and market risks. Input data include historical data on land productivities for various crops.

Consider a farm which has an agricultural land with an area of $S$ hectares. We suppose that the land quality is homogeneous. The farmer have to choose a crop plan from $n$ crops $C_{1}, C_{2}, \ldots, C_{n}$, that is to choose an area for each crop, such that some constraints are satisfied and some objectives are optimized.

Consider the probability space $(\Omega, \mathrm{K}, \mathrm{P})$. Denote $I=\{1,2, \ldots, n\}$. For every $i \in I$, we define the random variables:

- $\quad \xi_{i}: \Omega \rightarrow \mathbf{R}_{+}$the crop market price functions

- $\quad \eta_{i}: \Omega \rightarrow \mathbf{R}_{+}$the crop productivity functions

$\eta_{i}$ is the quantity of crop $C_{i}$ that can be produced on a land area of one hectare and $\xi_{i}$ is the market price for one $\mathrm{kg}$ of crop $C_{i}$.

For every $i \in I$, denote by:

- $\quad a_{i}$ - the cost (in euro/ha) for cultivating crop $C_{i}$.

- $S_{i}$ - the crop $C_{i}$ market price per ha (in euro/ha). $\varsigma_{i}=\xi_{i} \eta_{i}, i \in I$. 
- $\beta_{i}=E\left(\varsigma_{i}\right)$ - the expected market price for crop $C_{i}$ (in euro/ha).

- $\quad x_{i}$ - the decision variable representing the area (in ha) cultivated with crop $C_{i}$.

- $\quad\left[M_{1}, M_{2}\right]$ - the range (in euro) for the sum of money available for investment.

- $q_{i}$ - the lower bound for the crop $C_{i}$ yield, necessary to be obtained (contractual levels).

- $\quad p_{i}=\frac{q_{i}}{E\left(\eta_{i}\right)}$ - the lower bound for the land area cultivated with crop $C_{i}$ (in ha).

The yield of crop $C_{i}$ is equal to $\eta_{i} x_{i}, i \in I$. When the land allocation of crops is $\mathbf{x}=\left(x_{1}, x_{2}, \ldots, x_{n}\right)$, the cultivation cost is equal to $\sum_{i=1}^{n} a_{i} x_{i}$.

Consider the random vector $\varsigma=\left(\varsigma_{1}, \varsigma_{2}, \ldots, \varsigma_{n}\right)$ and its vector of means $\boldsymbol{\beta}=\left(\beta_{1}, \beta_{2}, \ldots, \beta_{n}\right)$.

The return (respectively the expected return) obtained when the crop plan $\mathbf{x}=\left(x_{1}, x_{2}, \ldots, x_{n}\right)$ is used is equal to:

$$
\begin{aligned}
& \varsigma^{T} \mathbf{x}=\sum_{i=1}^{n} \varsigma_{i} x_{i}=\sum_{i=1}^{n} \xi_{i} \eta_{i} x_{i} \\
& E\left[\varsigma^{T} \mathbf{x}\right]=\sum_{i=1}^{n} E\left(\xi_{i} \eta_{i}\right) x=\sum_{i=1}^{n} \beta_{i} x_{i}=\boldsymbol{\beta}^{T} \mathbf{x} .
\end{aligned}
$$

For every $i, j \in I$, denote

$c_{i j}=\operatorname{cov}\left(\varsigma_{i}, \varsigma_{j}\right)=E\left[\varsigma_{i} \varsigma_{j}\right\rfloor-E\left[\varsigma_{i}\right] \cdot E\left\lfloor\varsigma_{j}\right\rfloor$.

Denote by $\mathbf{C}=\left(c_{i j}\right)$ the covariance matrix.

We shall consider two symmetric risk measures:

- the variance

- the mean absolute deviation.

The variance of the return is:

$$
f_{1}(\mathbf{x})=\operatorname{Var}\left(\varsigma^{T} \mathbf{x}\right)=\sum_{i=1}^{n} \sum_{j=1}^{m} c_{i j} x_{i} x_{j}=\mathbf{x}^{T} \mathbf{C} \mathbf{x} .
$$

The mean absolute deviation of the return is:

$$
f_{2}(\mathbf{x})=E\left[\left|(\boldsymbol{\varsigma}-\boldsymbol{\beta})^{T} \mathbf{x}\right|\right]
$$

A first group of constraints of the models is the following:
- The area available for cultivation is equal to $S$. This constraint could be written as $\mathbf{e}^{T} \mathbf{x} \leq S$. It will be called the land constraint.

- The crop plan budget is in the range $\left[M_{1}, M_{2}\right]$. This constraint could be written as:

$M_{1} \leq \mathbf{a}^{T} \mathbf{x} \leq M_{2}$.

This will be called the budget constraint .

- The expected amount of each crop is greater than the demand (contracted quantities). The yield of crop $C_{i}$ is equal to $\eta_{i} x_{i}$. The expected amount of crop $C_{i}$ should be greater than $q_{i}$, that is:

$E\left(\eta_{i} x_{i}\right)=E\left(\eta_{i}\right) x_{i} \geq q_{i}$. If we denote $p_{i}=\frac{q_{i}}{E\left(\eta_{i}\right)}$ we shall have $x_{i} \geq p_{i}$. If $\mathbf{p}=\left(p_{1}, p_{2}, \ldots, p_{n}\right)$ then the constraint can be written in vector form as $\mathbf{x} \geq \mathbf{p}$. This will be called the demand constraint.

\subsection{Minimum financial risk models}

In the following we shall state two minimum financial risk models for crop planning. In the frame of this models the farmer tries to find an optimal allocation of land area to crops that minimize the financial risk, taking into account the constraints from the first group of constraints and in addition the following constraint: the expected net return is greater or equal than the user parameter $W$.

For $i \in\{1,2\}$ we have:

$(\mathrm{R}(i))\left\{\begin{array}{l}\min \left\lfloor f_{i}(\mathbf{x})\right\rfloor \\ (\boldsymbol{\beta}-\mathbf{a})^{T} \mathbf{x} \geq W \\ \mathbf{e}^{T} \mathbf{x} \leq S \\ M_{1} \leq \mathbf{a}^{T} \mathbf{x} \leq M_{2} \\ \mathbf{x} \geq \mathbf{p}\end{array}\right.$

An important problem is to determine the range for the user parameters $M_{1}, M_{2}$ and $W$. Let

$$
\begin{aligned}
& M_{1}^{\min }=\min \left\{\mathbf{a}^{T} \mathbf{x}: \mathbf{e}^{T} \mathbf{x} \leq S, \mathbf{x} \geq \mathbf{p}\right\} \\
& M_{2}^{\max }=\max \left\{\mathbf{a}^{T} \mathbf{x}: \mathbf{e}^{T} \mathbf{x} \leq S, \mathbf{x} \geq \mathbf{p}\right\}
\end{aligned}
$$

Them the farmer should choose parameters $M_{1}$, $M_{2}$ such that: 
$M_{1}^{\min } \leq M_{1} \leq M_{2} \leq M_{2}^{\max }$.

Let $X\left(M_{1}, M_{2}\right)=$

$=\left\{\mathbf{x} \in \mathbf{R}^{n}: M_{1} \leq \mathbf{a}^{T} \mathbf{x} \leq M_{2}, \mathbf{e}^{T} \mathbf{x} \leq S, \mathbf{x} \geq \mathbf{p}\right\}$

$W_{1}=\min \left\{(\boldsymbol{\beta}-\mathbf{a})^{T} \mathbf{x}: \mathbf{x} \in X\left(M_{1}, M_{2}\right)\right\}$

$W_{2}=\max \left\{(\boldsymbol{\beta}-\mathbf{a})^{T} \mathbf{x}: \mathbf{x} \in X\left(M_{1}, M_{2}\right)\right\}$

Then the farmer should choose parameter $W$ in the range $\left[W_{1}, W_{2}\right]$.

In Figure 1 is displayed the decision making schema for the selection of the crop plan and the minimum risk crop planning model.

\subsection{Maximum expected net return models}

In the following we shall state two maximum expected net return models for crop planning. In the frame of these models the farmer tries to find an optimal allocation of land area to crops that maximize the net return taking into account the constraints of the first group and in addition the following constraint: the financial risk is smaller or equal than the user parameter $r$.

For $i \in\{1,2\}$ we have:

$(\mathrm{E}(i))\left\{\begin{array}{l}\max \left[(\boldsymbol{\beta}-\mathbf{a})^{T} \mathbf{x}\right] \\ f_{i}(\mathbf{x}) \leq r \\ \mathbf{e}^{T} \mathbf{x} \leq S \\ M_{1} \leq \mathbf{a}^{T} \mathbf{x} \leq M_{2} \\ \mathbf{x} \geq \mathbf{p}\end{array}\right.$

The user parameters $M_{1}, M_{2}$ should be chosen as it was shown before.

Let:

$$
\begin{aligned}
& r_{1}=\min \left\{f_{i}(\mathbf{x}): M_{1} \leq \mathbf{a}^{T} \mathbf{x} \leq M_{2}, \mathbf{e}^{T} \mathbf{x} \leq S, \mathbf{x} \geq \mathbf{p}\right\} \\
& r_{2}=\min \left\{f_{i}(\mathbf{x}): M_{1} \leq \mathbf{a}^{T} \mathbf{x} \leq M_{2}, \mathbf{e}^{T} \mathbf{x} \leq S, \mathbf{x} \geq \mathbf{p}\right\}
\end{aligned}
$$

Then the farmer should choose parameter $r$ in the range $\left[r_{1}, r_{2}\right]$.

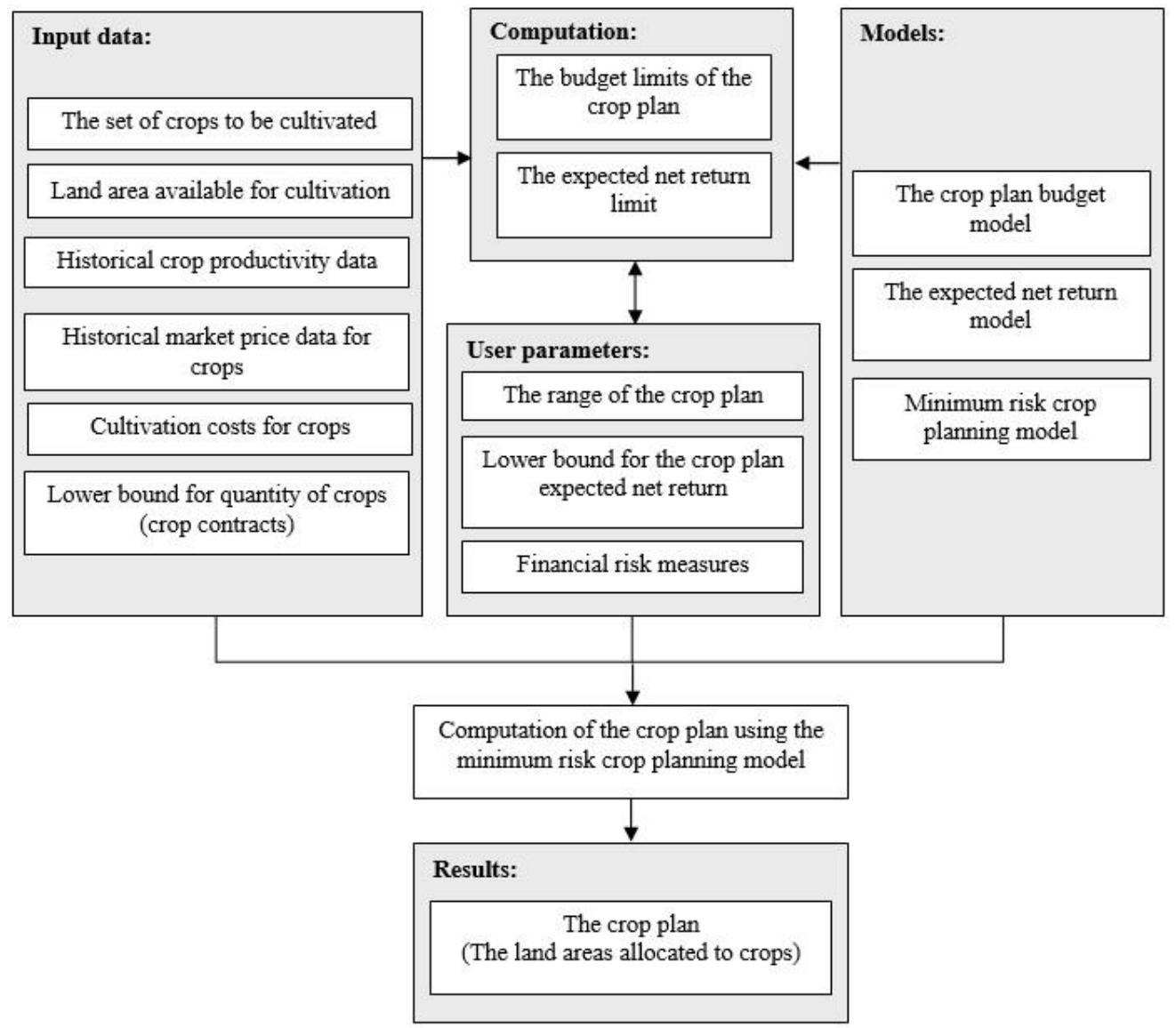

Figure 1. The decision process for the crop plan and the minimum risk crop planning model. 


\section{The Models that Contain Historical Data}

In order to solve the above mentioned models $R(i), i \in\{1,2\}$ we shall formulate $\bar{R}(i), i \in\{1,2\}$ models that are defined with the help of historical data. The $\bar{R}(i) \quad i \in\{1,2\}$ models are good approximations of $R(i), i \in\{1,2\}$ models.

We consider historical data on:

- crop market prices and

- crop productivities in a given horizon of time.

More precisely we consider that crop market prices and crop productivities at moments $t=1,2, \ldots, m$ are available to our study.

Let:

- $\quad a_{i}$ - be the cost for cultivating the crop $C_{i}$ (in euro/ha).

- $\quad q_{i}$ - the lower bound for the crop $C_{i}$ yield necessary to be obtained (contractual levels).

- $\quad p_{i}=\frac{q_{i}}{E\left(\eta_{i}\right)}$ - the lower bound for the area allocated to crop $C_{i}$

- $\quad \xi_{i t}$ - the crop market price for one $\mathrm{kg}$ of crop $C_{i}$ at moment $t$.

- $\quad \eta_{i t}$ - the crop productivity

- $C_{i}$ - the amount of crop $C_{i}$ obtained at moment $t$ if one hectare of land is cultivated .

- $\quad r_{i t}=\xi_{i t} \eta_{i t}$ is the price of crop $C_{i}$ obtained at moment $t$ from one hectare of land.

The sample mean of $\beta_{i}$ is:

$$
\bar{\beta}_{i}=\frac{1}{m} \sum_{t=1}^{m} r_{i t} .
$$

The sample variance of the net return for the crop plan $\mathbf{x}=\left(x_{1}, x_{2}, \ldots, x_{n}\right)$ is equal to:

$$
g_{1}(\mathbf{x})=\sum_{i=1}^{n} \sum_{j=1}^{n} \bar{c}_{i j} x_{i} x_{j}=\mathbf{x}^{T} \overline{\mathbf{C}} \mathbf{x}
$$

where $\overline{\mathbf{C}}=\left(\bar{c}_{i j}\right)$ and

$$
\bar{c}_{i j}=\frac{1}{m} \sum_{t=1}^{m}\left(r_{i t}-\frac{1}{m} \sum_{s=1}^{m} r_{i s}\right)\left(r_{j t}-\frac{1}{m} \sum_{s=1}^{m} r_{j s}\right)
$$

The sample mean absolute deviation for the crop plan $\mathbf{x}=\left(x_{1}, x_{2}, \ldots, x_{n}\right)$ is equal to:

$$
g_{2}(\mathbf{x})=\frac{1}{m} \sum_{t=1}^{m}\left|\sum_{i=1}^{n} r_{i t} x_{i}-\frac{1}{m} \sum_{s=1}^{m} \sum_{i=1}^{n} r_{i s} x_{i}\right|
$$

In order to solve the models $\mathrm{R}(i)$ and $\mathrm{E}(i)$, $i \in\{1,2\}$ we shall consider the associated models $\bar{R}(i)$ and $\bar{E}(i)$ in which the financial risk measures are computed based on sample variance or on the sample mean absolute deviation and the vector $\boldsymbol{\beta}=\left(\beta_{1}, \beta_{2}, \ldots, \beta_{n}\right)$ of means is replaced with the vector $\overline{\boldsymbol{\beta}}=\left(\bar{\beta}_{1}, \bar{\beta}_{2}, \ldots, \bar{\beta}_{n}\right)$ of sample means.

$$
\bar{R}(i)\left\{\begin{array}{l}
\min \left[g_{i}(\mathbf{x})\right] \\
(\overline{\boldsymbol{\beta}}-\mathbf{a})^{T} \mathbf{x} \geq W \\
\mathbf{e}^{T} \mathbf{x} \leq S \\
M_{1} \leq \mathbf{a}^{T} \mathbf{x} \leq M_{2} \\
\mathbf{x} \geq \mathbf{p}
\end{array}\right.
$$

The model $\bar{R}(1)$ is the following:

$$
\bar{R}(1)\left\{\begin{array}{l}
\min \left[\mathbf{x}^{T} \overline{\mathbf{C}} \mathbf{x}\right] \\
(\overline{\boldsymbol{\beta}}-\mathbf{a})^{T} \mathbf{x} \geq W \\
\mathbf{e}^{T} \mathbf{x} \leq S \\
M_{1} \leq \mathbf{a}^{T} \mathbf{x} \leq M_{2} \\
\mathbf{x} \geq \mathbf{p}
\end{array}\right.
$$

The model $\bar{R}(2)$ is the following:

$$
\bar{R}(2)\left\{\begin{array}{l}
\min \left[\frac{1}{m} \sum_{t=1}^{m}\left|\sum_{i=1}^{n} r_{i t} x_{i}-\frac{1}{m} \sum_{s=1}^{m} \sum_{i=1}^{n} r_{i s} x_{i}\right|\right] \\
(\overline{\boldsymbol{\beta}}-\mathbf{a})^{T} \mathbf{x} \geq W \\
\mathbf{e}^{T} \mathbf{x} \leq S \\
M_{1} \leq \mathbf{a}^{T} \mathbf{x} \leq M_{2} \\
\mathbf{x} \geq \mathbf{p}
\end{array}\right.
$$

The objective function of the model $\bar{R}(2)$ is nonlinear and non-smooth. The model $\bar{R}(2)$ can be transformed in an equivalent linear model by adding some supplementary variables. 
$\bar{R}^{\prime}(2) \quad\left\{\begin{array}{l}\min \left[\frac{1}{m} \sum_{t=1}^{m} z_{t}\right] \\ -z_{t} \leq h_{t}(\mathbf{x}) \leq z_{t}, t=1,2, \ldots, m \\ (\overline{\boldsymbol{\beta}}-\mathbf{a})^{T} \mathbf{x} \geq W \\ \mathbf{e}^{T} \mathbf{x} \leq S \\ M_{1} \leq \mathbf{a}^{T} \mathbf{x} \leq M_{2} \\ \mathbf{x} \geq \mathbf{p}, \quad \mathbf{z} \geq \mathbf{0}\end{array}\right.$

where:

$h_{t}(\mathbf{x})=\sum_{i=1}^{n} r_{i t} x_{i}-\frac{1}{m} \sum_{s=1}^{m} \sum_{i=1}^{n} r_{i s} x_{i}, t=1,2, \ldots, m$ and $\mathbf{z}=\left(z_{1}, z_{2}, \ldots, z_{m}\right)$

\section{Numerical Example}

Consider a set of 6 crops: $\mathrm{C}_{1}=$ wheat, $\mathrm{C}_{2}=$ barley, $\mathrm{C}_{3}=$ oats, $\mathrm{C}_{4}=$ maize, $\mathrm{C}_{5}=$ sunflower, $\mathrm{C}_{6}=$ soybean. An area of 100 hectares of arable land is available for cultivation.

We consider that historical data on crop market prices and crop productivities, in a given horizon of time, are available for our study. For the case, when some historical data are missing, the interested reader can find useful information in Fulga [7] and Radulescu [15]. The data in our numerical study are from an agricultural farm in the South Muntenia Region of Romania.

In Table 1 are displayed:

- in the third column the lower bound for the land areas allocated to crops (unit of measure is hectares)

- in the last column the lower bound for the quantities of crops, that is the demand (unit of measure is $\mathrm{kg}$ )

Table 1. The vectors $\mathbf{p}$ and $\mathbf{q}$

\begin{tabular}{|l|l|c|r|}
\hline Nr. & Crop & Vector $\mathbf{p}$ & Vector $\mathbf{q}$ \\
\hline 1. & Wheat & 6.5 & 17749 \\
\hline 2. & Barley & 3.2 & 7855 \\
\hline 3. & Oats & 3.1 & 5465 \\
\hline 4. & Corn & 5.7 & 18508 \\
\hline 5. & Sunflower & 4.5 & 6930 \\
\hline 6. & Soybean & 2.0 & 3614 \\
\hline
\end{tabular}

The horizon of time for historical data is 2006 2012. The direct payments for cultivated land will be 139 euro/ha.

We solve the minimum risk models with the variance and mean absolute deviation as risk measures. In the third (resp. fourth) column of Table 2 are displayed the optimal solution of the model $\bar{R}(1)$ (resp. of the model $\bar{R}^{\prime}(2)$ ).

Let $\overline{\bar{R}}(1)$ be the model $\bar{R}(1)$ in which the variance of the return is replaced with the standard deviation of the return. We solve models $\overline{\bar{R}}(1)$ and $\bar{R}^{\prime}(2)$ for several values of the parameter $W$ in the range $[13285 ; 49822]$.

The efficient frontiers of the models $\overline{\bar{R}}(1)$ and $\bar{R}^{\prime}(2)$ (that is the graphs of the optimal values of objective functions as a function of parameter $W$ ) are displayed in Figure 2.

The upper graph represents the efficient frontier corresponding to the minimum risk model with standard deviation as a risk measure. The lower graph represents the efficient frontier corresponding to the minimum risk model with the mean absolute deviation as a risk measure.

Table 2. Land area allocated to crops for the two risk measures and for $W=28944$ euro

\begin{tabular}{|l|l|r|r|}
\hline $\begin{array}{l}\text { Nr } \\
\text { crt. }\end{array}$ & Crop & $\begin{array}{c}\text { Land area } \\
\text { for the } \\
\text { variance as } \\
\text { a risk } \\
\text { measure }\end{array}$ & $\begin{array}{c}\text { Land area for } \\
\text { the mean } \\
\text { absolute } \\
\text { deviation as a } \\
\text { risk measure }\end{array}$ \\
\hline 1 & Wheat & 6.5 & 6.5 \\
\hline 2 & Barley & 3.2 & 3.2 \\
\hline 3 & Oats & 24.9 & 12.0 \\
\hline 4 & Corn & 5.7 & 24.0 \\
\hline 5 & Sunflower & 4.5 & 4.5 \\
\hline 6 & Soybean & 30.9 & 2.0 \\
\hline
\end{tabular}

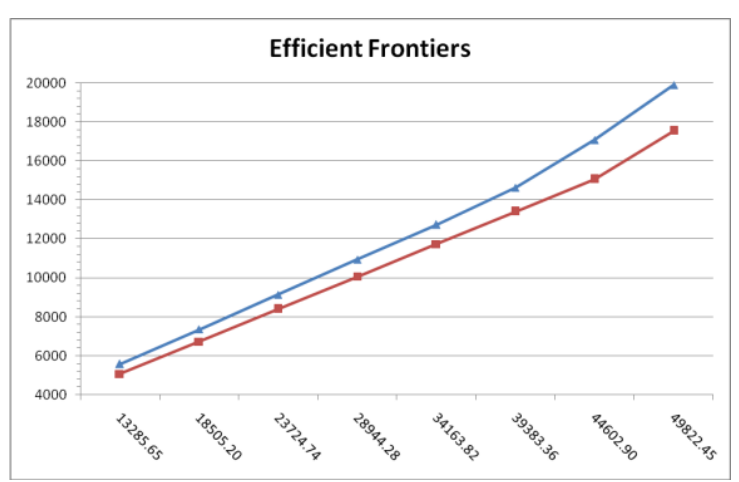

Figure 2. Efficient frontiers of the minimum financial risk models 


\section{Conclusion}

In this paper we developed several crop decision planning models that help farmers make appropriate decisions for selecting crops and allocating land to crops under weather and price uncertainties. The models were solved with QP and the LP solvers from GAMS. A numerical result for the minimum financial risk model for crop planning is analyzed. The data are from a farm located in the South Muntenia region. Further developments of the models presented above may include several soil types. Also, in the crop decision model, optional crops may be included, besides the mandatory crops (that is crops for which there exist demand). In this case the crop models will fall in the category of mixed integer models.

\section{Acknowledgements}

This work was supported by a grant of the Romanian National Authority for Scientific Research, CNCS - UEFISCDI, project number PN-II-ID-PCE-2011-3-0908.

\section{REFERENCES}

1. BARKLEY, A. P., H. H. PETERSON, J. SHROYER, Wheat Variety Selection to Maximize Returns and Minimize Risk: An Application of Portfolio Theory, Journal of Agricultural and Applied Economics, vol. 42(1), 2010, pp. 39-55.

2. BLANK, S. C., Returns to Limited Crop Diversification. Western Journal of Agricultural Economics, no. 15, 1990, pp. 204-212.

3. BLANK, S. C., C. A. CARTER, J. McDONALD, Is the Market Failing Agricultural Producers Who Wish to Manage Risks? Contemporary Economic Policy, no.15, 1997, pp. 103-112.

4. BLANK, S. C., Producers Get Squeezed up the Farming Food Chain: A Theory of Crop Portfolio Composition and Land Use. Review of Agricultural Economics, no. 23, 2001, pp. 404-422.

5. COLLENDER, R. N., Estimation Risk in Farm Planning under Uncertainty. American Journal of Agricultural Economics, no. 71, 1989, pp. 996-1002.
6. FREUND, R. J., The Introduction of Risk into a Programming Model. Econometrica, no. 24, 1956, pp. 253-263.

7. FUlGA, C., Convexification Technique and Portfolio Optimization, Studies in Informatics and Control, ISSN 1220-1766, vol. 22(4), 2013, pp. 285-290.

8. HARDAKER, J. B., R. B. M. HUIRNE, J. R. ANDERSON, G. LIEN, Coping with Risk in Agriculture, 2nd ed., CABI Publishing, Oxfordshire, 2004.

9. HAZELL, P. B. R, A Linear Alternative to Quadratic and Semivariance Programming for Farm Planning under Uncertainty. American Journal of Agricultural Economics, no.53, 1971, pp. 53-62.

10. HAZELL, P. B. R., R. D. NORTON, Mathematical Programming for Economic Analysis in Agriculture, Macmillan, New York, 1986.

11. MCCARL, B. A., Agricultural Impact Analysis using GAMS Including Firm Level Risk. Working Paper of the Department of Agricultural Economics, 1998, Texas A \& M University.

12. NALLEY, L. L., A. P. BARKLEY, Using Portfolio Theory to Enhance Wheat Yield Stability in Low-income Nations: An Application in the Yaqui Valley of Northwestern Mexico, Journal of Agricultural and Resource Economics, vol. 35(2), 2010, pp. 334-347.

13. RADULESCU, M., S. RADULESCU, C. Z. RADULESCU, Mathematical Models for Optimal Asset Allocation, (Romanian). Editura Academiei Române, Bucureşti, 2006.

14. RĂDULESCU, C. Z., RĂDULESCU M., A Decision Support Tool based on a Portfolio Selection Model for Crop Planning Under Risk, Studies in Informatics and Control, vol. 21(4), 2012, pp. 377-382.

15. RĂDULESCU, M., RĂDULESCU, C. Z., Mean-Variance Models with Missing Data, Studies in Informatics and Control, vol. 22(4), 2013, pp. 299-306.

16. RĂDULESCU, C. Z., M. RĂDULESCU, Gh. ZBĂGANU, A Portfolio Theory 
Approach to Crop Planning under Environmental Constraints, Annals of Operations Research, vol. 219, 2014, pp. 243-264.

17. ROMERO, C., Una aplicación del modelo de Markowitz a la selección de planes de variedades de manzanos en la provincia de Lérida. Revista de Estudios Agro-sociales, no. 97, 1976, pp. 61-79.

18. ROMERO, C., T. REHMAN, Multiple Criteria Analysis for Agricultural Decisions, Second Edition, Volume 11 (Developments in Agricultural Economics) Elsevier, Amsterdam, 2003.

19. ROMERO, C., Risk Programming for Agricultural Resource Allocation: A Multidimensional Risk Approach. Annals of Operations Research, vol. 94, 2000, pp. 57-68.

20. VADNERE, S., V. K. PANDEY, Minimization of Instability in Crop Production through Optimal Regional Crop Planning using MOTAD Model, Agricultural situation in India, vol. 54(6), 1998, pp. 367-374.
21. WERNERS, S. E., E. ERDÉLYI, I. SUPIT, Use of Modern Portfolio Theory to Evaluate Diversification of Agricultural Land Use as an Adaptation to Climate Risks in the Tisza River Basin, in Ford, James, Berrang Ford, Lea (Eds.) Climate Change Adaptation in Developed Nations, From Theory to Practice, Series: Advances in Global Change Research, vol. 42, 2011, pp. 371-383.

22. ZIA, S. M., A Trade-off Between Expected Returns and Risk among Farmers of Rice-wheat Zone of Punjab, Pakistan, Journal of Economic Cooperation among Islamic Countries, vol. 18(4), 1997, pp. 155-170.

23. ZIMET, D. J., T. H. SPREEN, A Target MOTAD Analysis of a Crop and Livestock Farm in Jefferson County, Florida, Southern Journal of Agricultural Economics vol. 18(2), 1986, pp. 175-185. 